https://helda.helsinki.fi

Teachers' attitudes to and beliefs about web-based

Collaborative Learning Environments in the context of an international implementation

\author{
Kollias, Vassilios
}

2005

Kollias , V , Mamalougos , N , Vamvakoussi , X , Lakkala , M \& Vosniadou , S 2005 , '

Teachers' attitudes to and beliefs about web-based Collaborative Learning Environments in the context of an international implementation ' , Computers \& Education , vol. 45 , no. 3 , pp. 295-315 . https://doi.org/10.1016/j.compedu.2005.04.012

http://hdl.handle.net/10138/27964

https://doi.org/10.1016/j.compedu.2005.04.012

publishedVersion

Downloaded from Helda, University of Helsinki institutional repository.

This is an electronic reprint of the original article.

This reprint may differ from the original in pagination and typographic detail.

Please cite the original version. 


\title{
Teachers' attitudes to and beliefs about web-based Collaborative Learning Environments in the context of an international implementation
}

\author{
Vassilios Kollias ${ }^{\mathrm{a}, *}$, Nektarios Mamalougos ${ }^{\mathrm{b}, \mathrm{c}}$, Xenia Vamvakoussi ${ }^{\mathrm{c}}$, \\ Minna Lakkala ${ }^{\mathrm{d}}$, Stella Vosniadou ${ }^{\mathrm{c}}$ \\ a Department of Primary Education, University of Thessaly, Argonauton \& Fillelinon 382 21, Volos, Greece \\ ${ }^{\mathrm{b}}$ Physics Laboratory, Department of Physics, University of Athens, Greece \\ ${ }^{\mathrm{c}}$ Cognitive Science and Educational Technology Laboratory, Department of Methodology, History and Theory of Science, \\ University of Athens, Greece \\ ${ }^{\mathrm{d}}$ Centre for Research on Networked Learning and Knowledge Building, Department of Psychology, \\ University of Helsinki, Finland
}

\begin{abstract}
Fifty-six teachers, from four European countries, were interviewed to ascertain their attitudes to and beliefs about the Collaborative Learning Environments (CLEs) which were designed under the Innovative Technologies for Collaborative Learning Project. Their responses were analysed using categories based on a model from cultural-historical activity theory [Engeström, Y. (1987). Learning by expanding: An activitytheoretical approach to developmental research. Helsinki: Orienta-Konsultit; Engeström, Y., Engeström, R., $\&$ Suntio, A. (2002). Can a school community learn to master its own future? An activity-theoretical study of expansive learning among middle school teachers. In G. Wells \& G. Claxton (Eds.), Learning for life in the 21st century. Oxford: Blackwell Publishers]. The teachers were positive about CLEs and their possible role in initiating pedagogical innovation and enhancing personal professional development. This positive perception held across cultures and national boundaries. Teachers were aware of the fact that demanding planning was needed for successful implementations of CLEs. However, the specific strategies through which the teachers can guide students' inquiries in CLEs and the assessment of new competencies that may
\end{abstract}

\footnotetext{
* Corresponding author. Tel.: +30 24210 74992; fax: +30 2421074786.

E-mail address: vkollias@uth.gr (V. Kollias).
} 
characterize student performance in the CLEs were poorly represented in the teachers' reflections on CLEs. The attitudes and beliefs of the teachers from separate countries had many similarities, but there were also some clear differences, which are discussed in the article.

(C) 2005 Elsevier Ltd. All rights reserved.

Keywords: Cooperative/collaborative learning; National school culture; Evaluation methodologies; Distributed learning environments

\section{Introduction}

The European Innovative Technologies for Collaborative Learning Project (ITCOLE) concentrated on creating software tools that support web-based Collaborative Learning Environments (CLE) (see Rubens, Emans, Leinonen, Skarmeta, \& Simons, this issue) and on delineating efficient pedagogical practices for CLEs, on testing and refining them and eventually disseminating them throughout the European education landscape. The pedagogical partners of the project consisted of four research groups from four European countries: Finland, Greece, Italy and the Netherlands (Ligorio \& Veermans, this issue).

A worldwide study (Kozma, 2003) of teachers' and students' practices in classrooms, where innovative pedagogical practices supported by technology have been introduced, showed that two patterns of classroom practice, "Student Collaborative Research" and "Information Management", are more likely to be associated with new pedagogical skills for teachers. The same patterns were associated with the acquisition of ICT, problem solving and collaboration skills for students. Both patterns have strong resemblances with the expected practices in the CLEs that were implemented during the ITCOLE project. Moreover, CLEs have influenced the development of the Computer Supported Collaborative Learning paradigm (Dimitrakopoulou \& Petrou, in press; Koschmann, 1996). In recent literature, CLEs have been associated with the notion of powerful learning environments characterized by special emphasis on the development of intentional learners and the collaborative construction of knowledge within learning communities. Support for metacognition, model building, and emphasis both on the process and on the product are also important aspects of the developed powerful learning environments (Vosniadou, 2001; Vosniadou \& Kollias, 2003).

However, the successful implementation of CLEs depends on sensitive decisions that teachers have to make in their everyday practice. It has been pointed out that such decisions depend on teachers' attitudes to and beliefs about the particular learning environment (Schulman, 1986). Therefore, the analysis of teachers' conceptions of CLEs can provide insights on the prerequisites for their successful implementation.

According to Dexter, Anderson, and Becker (1999) "The teachers who had adopted more progressive teaching practices over time felt that computers helped them change, but they did not acknowledge computers as catalyst for change; instead they cited reflection upon experience, classes taken, and the context or culture of the school." (p. 221). Therefore, if teachers' conceptions of CLEs reveal that CLEs facilitated teachers' reflections upon their experience, awareness of the importance of the school culture towards educational innovation, and awareness for the need of professional improvement, then we would have reasons to expect that CLEs are particularly promising in facilitating teachers to adopt more progressive teaching practices. 
In this study, we interviewed teachers from the four countries, who implemented web-based CLEs in their own classrooms, while participating in the ITCOLE project. The interviews took place after the completion of the project and the questions referred to different aspects of the CLE implementation, as well as to the teachers' own reflections on the implementations of CLEs.

CLEs constitute activity systems which introduce transformations in collective practices. In order to specify the main dimensions that define teachers' attitudes to and beliefs about CLEs, we adopted the theoretical approach developed by Engeström (1987) and Engeström et al. (2002). Their model of an activity system is based on cultural-historical activity theory and introduces six important dimensions, along with the dynamics among them: Subject, Object (the goal of the activity system), Norms, Division of Labour, Community and Instruments.

Applying this framework to a traditional classroom in its day to day operation, we could assign the teacher to the dimension 'Subject', the learning goals for the students to the dimension 'Object', the implicit and explicit rules that structure social interaction to the dimension 'Norms', the prescribed roles of the teacher and the student to the dimension 'Division of Labour', the group of students and teacher to the dimension 'Community' and different educational tools to the dimension 'Instruments'. In the case of CLEs, however, the implementation of the innovation introduces tensions that change the content of the dimensions, at least with respect to teachers' attitudes to and beliefs about CLEs.

First, we expected considerable transfer of learning responsibilities from the teacher, to the students. Having both intra-group collaboration in front of the PCs and inter-group collaboration via the collaborative software, facilitates change in the division of labour inside the classroom that brings forth the 'Teacher' and the 'Student' as subjects struggling towards a new equilibrium. It was expected that the strain created between the dimensions 'Subject' and 'Division of Labour' would make the new dimensions 'Student' and 'Teacher' salient in the teachers' attitudes to and beliefs about of CLEs. It was also expected that the teachers would perceive CLEs as learning environments that are strongly student-centred and that give affordances to students to take more learning responsibilities.

Second, we expected that the characteristics of the software would be a prominent feature in the teachers' conceptions of CLEs. Hence, we expected that the dimension 'Instruments' would appear in the teachers' conceptions of CLEs mainly as the dimension 'Software'.

Third, we hypothesized that the contradictions between CLE designs, school organization affordances, and national curricula directions would make salient in the 'Community' dimension a vertical dimension referring to CLE's position inside the institutional setting of education. The school organization and the national curriculum are structures through which the community that realizes the CLE, comprised by the teacher and the students, interacts with the larger community and its educational agenda. Moreover, the change in the distribution of labour creates opportunities for changing attitudes between the community of teachers and the community of students. This is a horizontal dimension within the 'Community' dimension. We expected that the CLE implementation would increase the trust that the teachers felt about the students' ability to direct their learning and hence that this dimension would be represented in the teachers' conceptions of CLEs.

Fourth, we expected that the prominence of collaboration as a feature of CLEs would affect the dimensions 'Norms' and 'Object' in the teachers' conceptions. 'Norms' were going to be affected by the opportunities and challenges of establishing fruitful collaboration among students in the 
classroom. The 'Object' of the activity in the CLEs would be affected by teachers' expectations of accountability for the implemented innovation. Accountability would include not only reference to learning gains (in a declarative sense) but also references to the quality of collaboration and to the acquisition of different skills among which ICT skills were expected to be prominent. The innovation might also create an awareness of the need for new kinds of assessment in order to capture the added value of the modern learning environments.

Finally, we assumed that, in the process, teachers would come to see CLEs as working systems, where student performances that show understanding get integrated with teachers' ongoing assessment and feedback to the students (Perkins, 1995). The presence of these features in the CLEs is highly valued as indicative of a qualitative change in the classroom.

Research in cognitive science (Bransford, Brown, \& Cocking, 1999) points that teachers will interpret CLEs based on their prior understanding of learning environments. In the methodology section, we present short accounts of the educational system of each one of the four participating countries. We also mention the pedagogical issues that were of importance for each group of researchers and were discussed in their initial contacts with the participating teachers.

\section{Methodology}

\subsection{Settings}

The participating countries differed in the emphasis they gave in introducing the project to the teachers. The Finnish school culture is very autonomous even on the level of developing school curriculum, and Finnish teachers are, in general, rather used to implement new learning methods. The participating teachers were trained to apply a rather demanding pedagogical model of progressive inquiry in their CLE implementations (Hakkarainen, 2003; Hakkarainen, Rahikainen, Lakkala, \& Lipponen, 2002). In contrast, the Greek teachers often felt uncertain about how to introduce ICT in their classroom (Kollias, Mamalougos, Vamvakoussi, \& Vosniadou, 2003; Kollias \& Vosniadou, 2002; Vosniadou \& Kollias, 2001). For this reason, this project was introduced to them with a focus on students' prior knowledge, free expression and discussion of their own opinions, and new distribution of the responsibility for learning inside the classroom between students and teacher (Vosniadou, 2001).

The educational theories to which the Italian partners referred emphasize the role of collaborative learning and co-constructivism (Ligorio, Cesareni, Mancini, \& Talamo, 2002). During the project, the participating teachers were explicitly asked to put in practice the principles of these theories. Finally, in the case of Dutch education, emphasis was given on skills of learning, thinking, collaboration and regulation (Molenaar, Scheltinga, Simons, \& Sligte, 2002). The Dutch teachers showed interest towards developing authentic learner-centred learning contexts, and supporting students into 'learning how to learn' within the CLEs.

\subsection{Participants}

Fifty-six teachers from Finland, Greece, Italy and the Netherlands who implemented CLEs in their classrooms participated in this study. There were teachers from both primary and secondary 
education. Table 1 presents the number of the participating teachers from each country and their distributions relative to educational level, gender, age, years of teaching and experience in CLEs.

\subsection{Data collection}

After the end of the implementation of the CLEs, the four research groups arranged meetings with the participating teachers. In these meetings, the teachers were interviewed relative to different aspects of their experience with the CLEs. The questions of the interviews did not directly ask for the teachers' attitudes to and beliefs about CLEs. The teachers were asked to actively participate to the construction and maintenance of the CLEs, and the questions followed the unfolding of the CLEs' implementation.

More precisely, the questions asked (Table 2) were divided into five categories. They address: the management and the monitoring the CLE environment ('Leading' and 'Assessment'), the teachers' perception of some important general goals in the CLEs - such as collaboration and

Table 1

Number of participating teachers for each country and their distributions relative to educational level, gender, age, years of teaching and experience in CLEs

\begin{tabular}{lllllll}
\hline Nationality & $\begin{array}{l}\text { Number of } \\
\text { teachers }\end{array}$ & $\begin{array}{l}\text { Level: primary- } \\
\text { secondary }\end{array}$ & $\begin{array}{l}\text { Gender: } \\
\text { male-female }\end{array}$ & $\begin{array}{l}\text { Age: } \\
\text { average-SD }\end{array}$ & $\begin{array}{l}\text { Years of teaching: } \\
\text { average-SD }\end{array}$ & $\begin{array}{l}\text { Experience in CLEs: } \\
\text { much-some-none }\end{array}$ \\
\hline Finland & 15 & $6-9$ & $5-10$ & $38-7$ & $10-6$ & $4-5-6$ \\
Greece & 9 & $2-7$ & $7-2$ & $40-9$ & $12-9$ & $2-2-5$ \\
Italy & 22 & $16-6$ & $1-21$ & $45-7$ & $15-9$ & $3-2-17$ \\
Netherlands & 10 & $5-5$ & $7-3$ & a & a & $0-1-9$
\end{tabular}

${ }^{\text {a }}$ Data not available.

Table 2

Questions asked in the interviews clustered in groups

\begin{tabular}{ll}
\hline Groups & Exact questions \\
\hline Leading & 1. As a teacher, how did you help and guide students during the project? \\
Assessment & 2. Carrying out the project how did you deal with the issue of assessment? What did you \\
choose to assess? & 3. Can the software tool facilitate you in the way you are usually assessing your students? \\
Does it offer new possibilities for carrying out the assessments?
\end{tabular}
Alternative Opinions
4. Do you think the project succeeded in getting the students to collaborate? Was there a and Collaboration benefit in collaboration? If yes, what exactly was the benefit?
5. Do you think that the project succeeded in getting the students to express their alternative opinions more openly? What were the advantages or disadvantages (if any)?

Reflection

6. Now that you have implemented the project, what would you do differently next time?

7. Did the use of the software change your usual teaching practices in any way?

8 . Did the project make you reconsider any of your beliefs about teaching and learning?

Positive and Negative Experiences 
open expression of students' opinions ('Alternative Opinions and Collaboration'), the teachers' reflections on the whole project with respect to the lessons that they learned through their participation in the project and the influence that it had for their further planning ('Reflection'), and finally the recollection of positive and negative experiences from the project ('Positive and Negative Experiences').

\subsection{Data analysis}

The teachers' answers were audio-recorded, transcribed and translated in English by the researchers in each of the four participating countries. The transcribed text was divided in sections called 'teachers' comments' based on the principles that (a) each comment should belong to an answer of a specific question and (b) each comment should belong to only one of the set of categories. In order to create the set of categories on which the comments were assigned, the following procedure was followed.

The main categories of comments were created based on the activity-theoretical model presented in Section 1. Due to the prominence of the change in the division of labour in CLEs, the categories 'Subject' and 'Division of Labour' were replaced by the categories 'Student' and 'Teacher', which refer to the changing roles and the concerns of these main actors. The category 'Object' was replaced by the category 'Accountability' which captures the teachers concerns about the effectiveness of the whole CLE activity system. The other categories were 'Software', 'Communities', 'Norms' and a category called 'New Classroom' that refers to comments that present glimpses of qualitatively new learning processes in the classroom.

Further examination of the transcribed text resulted in the creation of subcategories leading to the final set of categories presented in Table 3. More precisely, in the main category 'Student', we differentiated comments referring to the changing division of labour and comments that emphasized the new motivational potential of the CLEs. In the main category 'Teachers', we distinguished comments referring to different aspects of the teacher's role. We also discerned comments that related CLEs with broader pedagogical teacher concerns and with the development of the teacher professional expertise. In the main category 'Community', in agreement with the discussion in Section 1, a vertical and a horizontal dimension were distinguished. In the main category 'Accountability', we singled out comments referring to learning gains, collaboration or skills. Finally, the main category 'New Classroom' was differentiated, based on whether the comments were referring to a well-knit organization of assessment and performance or to a sense of "flow" of the classroom work as the activity unravelled. Descriptions of the different categories are given in Appendix A. Examples of comments belonging to each category are reported in Section 3.

Comments that referred to issues outside of the aims of the interview were left out of the analysis. Two researchers rated the whole text, and the final agreement was above the $85 \%$ level.

The separation of the transcribed text into categorized 'teachers' comments' was used both towards performing a quantitative analysis and towards performing a qualitative analysis. In the case of the quantitative analysis, we used the patterns and correlations of percentage distributions of teachers' comments. In the case of the qualitative analysis, the categorization of the comments was used to extract the main themes that were coming out of the teachers' responses. 
Table 3

Main categories and final categories (including subcategories) of teachers' comments

\begin{tabular}{ll}
\hline Main categories & Categories \\
\hline Student & Division of Labour: student role \\
Motivating the student & Division of Labour: teacher role technical \\
Teacher & Division of Labour: teacher role planning \\
& $\begin{array}{l}\text { Division of Labour: teacher role performance } \\
\text { Long term pedagogical concerns }\end{array}$ \\
& Development of professional expertise \\
New Classroom & Accountability: integrated \\
& Activity system \\
Accountability & Learning gains \\
& Collaboration \\
Skills \\
Coftware & Software \\
Norms & Community: vertical \\
& Community: horizontal \\
\end{tabular}

\section{Results}

\subsection{Quantitative analysis}

Table 4 presents the frequency and percent of the teachers' comments for each group of questions clustered by country (the percentages' sum is $100 \%$ when adding all comments referring to the same country).

In Table 5, the teachers' comments are grouped based on their classification into categories and are clustered by country (The percentages add to $100 \%$ when adding all comments referring to the same country). The category 'Development of Professional Expertise' is worth noticing because it indicates the teachers' reflection about their progress as professionals which was generated through their participation in the CLEs.

In order to find common trends and differentiations among the teachers in different countries we first considered the distribution of teachers' comments for each of the main categories, for each nationality (Totals, in Table 5). Fig. 1 presents the plots of these percents (the percents of teachers' comments belonging to each of the main categories) per country.

The Greek teachers' comments were clearly different, with main differences being the prominence of the category 'Teacher', and the low frequency of the categories 'Software' and 'New Classroom'. The teachers from the other three countries present similar profiles: percents are evenly spread among 'Teacher', 'Student', 'Accountability', 'Software', 'New Classroom'. The Finnish teachers have more numerous comments referring to 'Student', while the Italian teachers refer more to the 'Software'. 
Table 4

Frequency and percent of teachers' comments for each group of questions, clustered by country and group of questions

\begin{tabular}{lll}
\hline Group of questions & $\begin{array}{l}\text { Number of } \\
\text { comments }\end{array}$ & $\begin{array}{l}\text { Percent of the total number } \\
\text { in each group of questions (\%) }\end{array}$ \\
\hline Finland & 11 & 10 \\
1. Leading & 17 & 15 \\
2. Assessment & 20 & 15 \\
3. Alternative opinions and collaboration & 21 & 15 \\
4. Reflection & 57 & 45 \\
5. Positive and Negative Experiences & & \\
Greece & 11 & 10 \\
1. Leading & 18 & 20 \\
2. Assessment & 18 & 20 \\
3. Alternative opinions and collaboration & 28 & 30 \\
4. Reflection & 17 & 20 \\
5. Positive and Negative Experiences & & \\
Italy & 17 & 15 \\
1. Leading & 7 & 5 \\
2. Assessment & 28 & 25 \\
3. Alternative opinions and collaboration & 24 & 20 \\
4. Reflection & 45 & 35 \\
5. Positive and Negative Experiences & & \\
The Netherlands & 8 & 10 \\
1. Leading & 11 & 10 \\
2. Assessment & 17 & 20 \\
3. Alternative opinions and collaboration & 28 & 30 \\
4. Reflection & 30 & 30 \\
5. Positive and Negative Experiences & & \\
& & \\
& & \\
& & \\
& &
\end{tabular}

We also analyzed how the categories of the teachers'comments were distributed among the different groups of questions in each country. Table 6 refers to a difference that comes prominent out of such a comparison with respect to the main category 'Student'.

In the Greek teachers' comments, the category 'Student' was prominent in the 'Reflection' group of questions. Since this group of questions strongly represents pedagogical issues that teachers struggle with, this is an indication that the changing role of the student was a greater concern for the Greek teachers than for the teachers of other nationalities. For the Finnish and the Dutch teachers, the same category was prominent in the 'Positive and Negative Experiences' questiongroup, indicating a concern for confirmatory evidence relative to educational choices (connected with empowering the student) that have been made and worked through. Finally, in the Italian teachers' comments the category 'Student' is strongly represented in the question-group 'Alternative Opinions and Collaboration', indicating an ease with sharing learning responsibility with students and concentration to the actual cognitive and social aspects of students' engagement in the CLEs. 
Table 5

Frequency and percent of teachers' comments in each category of teachers' comments, clustered by country

\begin{tabular}{|c|c|c|c|c|}
\hline & Finland & Greece & Italy & The Netherlands \\
\hline \multicolumn{5}{|l|}{ Student } \\
\hline Division of Labour: student role & $10 \%(13)$ & $4 \%(4)$ & $5 \%(6)$ & $7 \%(7)$ \\
\hline Motivating the student & $11 \%(14)$ & $5 \%(5)$ & $10 \%(12)$ & $7 \%(7)$ \\
\hline Totals & $21 \%$ & $10 \%$ & $15 \%$ & $15 \%$ \\
\hline \multicolumn{5}{|l|}{ Teacher } \\
\hline Division of Labour: teacher role technical & $3 \%(4)$ & $4 \%(4)$ & $0 \%(0)$ & $2 \%(2)$ \\
\hline Division of Labour: teacher role planning & $6 \%(8)$ & $11 \%(10)$ & $9 \%(11)$ & $7 \%(7)$ \\
\hline Division of Labour: teacher role performance & $10 \%(13)$ & $13 \%(12)$ & $4 \%(5)$ & $4 \%(4)$ \\
\hline Long term pedagogical concerns & $1 \%(1)$ & $4 \%(4)$ & $4 \%(5)$ & $9 \%(8)$ \\
\hline Development of professional expertise & $3 \%(4)$ & $12 \%(11)$ & $12 \%(15)$ & $11 \%(10)$ \\
\hline Totals & $24 \%$ & $45 \%$ & $30 \%$ & $33 \%$ \\
\hline \multicolumn{5}{|l|}{ New Classroom } \\
\hline Accountability: integrated & $7 \%(9)$ & $2 \%(2)$ & $7 \%(8)$ & $6 \%(6)$ \\
\hline Activity system & $10 \%(12)$ & $1 \%(1)$ & $7 \%(8)$ & $9 \%(8)$ \\
\hline Totals & $17 \%$ & $3 \%$ & $13 \%$ & $15 \%$ \\
\hline \multicolumn{5}{|l|}{ Accountability } \\
\hline Learning gains & $6 \%(8)$ & $9 \%(8)$ & $4 \%(5)$ & $4 \%(4)$ \\
\hline Collaboration & $2 \%(2)$ & $10 \%(9)$ & $8 \%(10)$ & $6 \%(6)$ \\
\hline Skills & $6 \%(8)$ & $0 \%(0)$ & $2 \%(2)$ & $3 \%(3)$ \\
\hline Totals & $14 \%$ & $18 \%$ & $14 \%$ & $14 \%$ \\
\hline \multicolumn{5}{|l|}{ Software } \\
\hline Software & $13 \%(16)$ & $5 \%(5)$ & $20 \%(24)$ & $12 \%(11)$ \\
\hline \multicolumn{5}{|l|}{ Community } \\
\hline Community: vertical & $7 \%(9)$ & $3 \%(3)$ & $3 \%(4)$ & $2 \%(2)$ \\
\hline Community: horizontal & $2 \%(2)$ & $8 \%(7)$ & $2 \%(2)$ & $4 \%(4)$ \\
\hline Totals & $9 \%$ & $11 \%$ & $5 \%$ & $6 \%$ \\
\hline \multicolumn{5}{|l|}{ Norms } \\
\hline Norms & $2 \%(3)$ & $8 \%(7)$ & $3 \%(4)$ & $5 \%(5)$ \\
\hline
\end{tabular}

\subsection{Qualitative analysis}

In the case of qualitative analysis, the comments that refer to each of the categories of Table 3 were read and there were extracted common themes referring to the teachers' attitudes to and beliefs about CLEs. Some of these themes were common for the teachers of all nationalities and some differentiated among the teachers from different countries. The examples mentioned are 


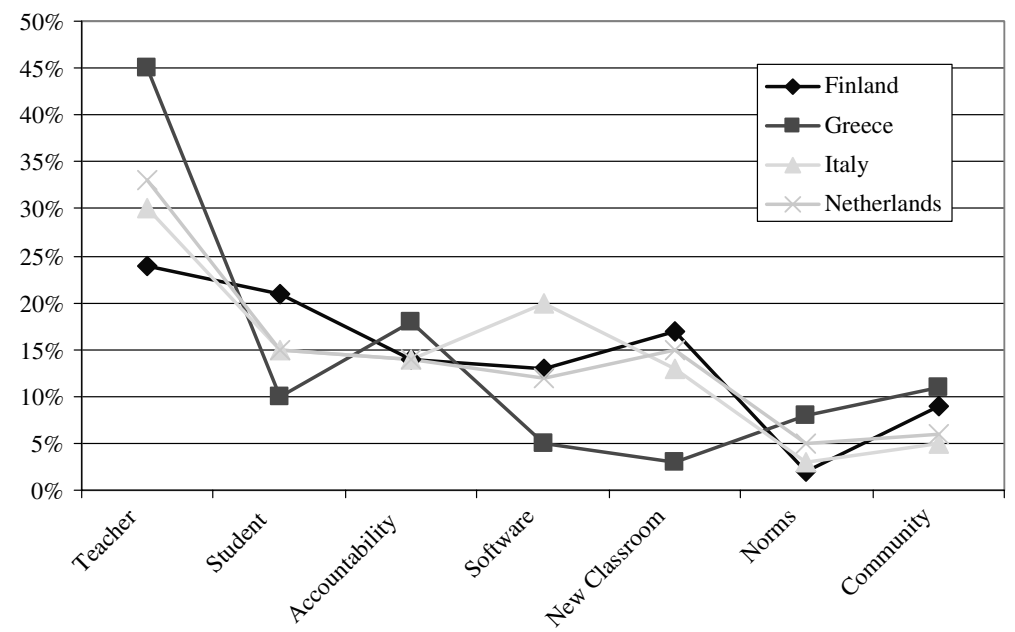

Fig. 1. Percent of teachers' comments belonging to each of the main categories of teachers' comments per country.

Table 6

Frequency and percent of teachers' comments belonging to the 'student' main category of teachers' comments, along the different groups of questions according to nationality

\begin{tabular}{lllll}
\hline Student & Finland & Greece & Italy & The Netherlands \\
\hline Leading & $4 \%(1)$ & $0 \%(0)$ & $6 \%(1)$ & $7 \%(1)$ \\
Assessment & $11 \%(3)$ & $0 \%(0)$ & $0 \%(0)$ & $0 \%(0)$ \\
Alternative opinions and collaboration & $37 \%(10)$ & $33 \%(3)$ & $72 \%(13)$ & $21 \%(3)$ \\
Reflection & $4 \%(1)$ & $56 \%(5)$ & $11 \%(2)$ & $21 \%(3)$ \\
Positive and Negative Experiences & $44 \%(12)$ & $11 \%(1)$ & $11 \%(2)$ & $50 \%(7)$ \\
\hline
\end{tabular}

characteristic comments from different teachers. In each case, the nationality, level of education, and gender of the teachers are mentioned.

\subsection{Teacher comments related to 'Students'}

\section{(a) Division of Labour: student role}

The teachers from all the countries described CLEs as student-centred environments, which give affordances for students to actually take more learning responsibilities.

This tool has allowed students to be more independent (Greece, primary, female).

Students understand you are there to help them if they are in troubles ... basically they do the work, they are the main actors (Italy, secondary, female).

Since the change in the student role is related to the change in teacher role, teachers regarded the transfer of responsibility to be rather challenging in the CLE environment. This was expressed either implicitly, as a post facto wish for having given more responsibility to the students, or explicitly by describing the difficulty the teachers felt in this process. 
It is hard, especially for older teachers, to give away responsibility. You give away the complete grip! Students have to learn how to give feedback (The Netherlands, primary, male).

In Finland and the Netherlands, CLEs were described as learning environments that are demanding for students, where they try hard to be successful. This belief came through either implicitly, by referring to the various demanding tasks that students had to perform (evaluating their and others work, searching information), or explicitly.

Collaborative writing of stories was challenging. Some of the groups were successful; some of them had difficulties with completing the process together: some students took dominative roles and did not share responsibilities, some of the students withdrew upon their own choice. One group split into two (Finland, primary, male).

(b) Motivating the students

In this category, the teachers expressed the belief that CLEs are highly motivating for students.

Students feel that they can participate in the lesson and that they can contribute in the group work. This makes it more interesting for them to participate. Moreover, even the better students, do not feel bored because even for them the task was demanding (Greece, secondary, female).

The most positive aspect I saw is that they were enthusiastic in doing something that remains on the internet, something which leaves a trace (Italy, secondary, female).

CLEs were also regarded as motivating for students who underachieve under usual classroom conditions or who are usually shy. There were no comments mentioning gifted students being bored because of being unchallenged. In the case of the Netherlands, in particular, CLEs were seen as environments where student motivation depends on the careful design of the learning environment. As time proceeds, initial motivation may evaporate if not supported:

The project lasted too long. The students' interest disappeared (The Netherlands, primary, male).

Moreover, the Dutch teachers mentioned differences on how eager the students were to participate:

I think it is a problem that some students want to continue working (and deepen their knowledge) and others students have a feeling that they have seen enough (The Netherlands, primary, male).

\subsection{Teacher comments related to 'Teachers'}

(a) Division of Labour: teacher role, technical

In all countries the teachers felt that in a CLE they might be overwhelmed by the students' need for technical advice. Usually, they felt they could face the challenge.

Only afterwards I realized that I had to use almost all the project time for technical guidance; even though I had time to guide in information search and process of inquiry, I did not have time to participate in knowledge building discourse, and I read the discussions later on during my free time (Finland, secondary, female). 
In the beginning I had to spend a lot of time guiding students in the use of Synergeia. As they eventually got used to it, they felt more at ease to work with it (The Netherlands, primary, male).

(b) Division of Labour: teacher role, planning

All the teachers expressed the strong belief that CLEs demand careful planning.

This type of learning environment demands careful preparation in order to carry out a project within a tight schedule (Finland, secondary, male).

Planning refers to having the computer room free, taking care of the social organization of the classroom (composition of groups), considering the different learning paths possible (differentiation among students), and creating the supportive structures necessary for the students to stay focused.

I think that one has to be prepared about different 'scenarios' of how the interaction in the classroom may play out. This is especially critical when one takes into account the differences among students and the different speed with which they proceed in the interaction (Greece, secondary, male).

I would take more time for the preparation (The Netherlands, secondary, male).

(c) Division of Labour: teacher role, performance

The teachers from the four countries differed in the specificity of their thinking about the teachers' guiding role in the classroom during the project. The teachers from Finland were the most articulate in this respect.

It was challenging to see how the students learned to search, to elaborate and to deepen their knowledge and especially to focus their research questions by themselves. The students needed a lot of guidance during these phases (Finland, secondary, male).

The fact that students' thinking is visible in the database helps me guide students better than before. As a teacher, I can also see, on what level students' thinking is, and how concretely or abstractly they can process knowledge (Finland, primary, female).

The Greek teachers referred to specific guidance incidences, focusing on their own activities in guiding in the CLEs.

We encouraged them to collaborate and make the best of their opportunity to communicate (turn to their fellow students for help, ask for clarifications, make their own ideas as clear as possible, explain). Occasionally, we pointed out things that needed to be better elaborated (Greece, primary, female).

The Italian teachers did not speak specifically about this aspect of CLEs, while the Dutch teachers made only a few relevant comments. It appears that the issue of teacher guidance in the CLEs was a hazy region for most teachers.

(d) Long term pedagogical concerns

Discussion about CLEs brings forth long term pedagogical concerns, putting the CLEs in a broader perspective. This dimension concerned, in an explicit way, mainly the Dutch teachers. 
These are basic skills. Students have to feel autonomous, appreciated and safe. This is necessary for learning. And it is very important in the rest of their life. To have an own opinion and be able to give arguments (The Netherlands, primary, male).

The issue appeared to a lesser degree in the Greek and Italian teachers' comments, while it was very rare for the Finnish teachers.

(e) Development of professional expertise

Finally, CLEs were seen as great facilitators of progress in professional expertise.

FLE was useful for me as a teacher. I learned more about students' thinking and I could guide students more precisely. I have got familiar with a totally new way of teaching and feeling of success (Finland, primary, female).

However I realize that I need to work more now, that I need to master new skills and that, although I will work more, I will need to defend myself against criticism from know-it-all parents (Greece, secondary, male).

This aspect of the teachers' experience of CLEs was unexpected to us, and it points to the CLEs' potential as instruments for developing teachers' pedagogical expertise.

\subsection{Teacher comments related to 'New classroom'}

(a) Accountability: integrated

In many comments by the Finnish, Italian and Dutch teachers, CLEs were seen as environments where assessment and instruction are integrated. This dimension was nearly nonexistent in the comments of the Greek teachers.

I always asked the following questions in the next lesson after the FLE3 sessions: (1) What was good in your work? (2) What aspects of your working could you still develop? (3) What was the usefulness of the starting question for you? In the final exam I asked, what issues helped you with your learning (Finland, secondary, female).

Synergeia is the place where the teacher does not grade students; you assess the collective work together with them (Italy, primary, female).

(b) Activity system

In certain occasions, speaking about CLEs brought forth the implemented vision of a new classroom: there were descriptions of the classrooms as a whole, and images of classroom "in flow".

The groups worked enthusiastically, and searched information for each other. The students were divided into groups according to their topics. The division of labour in the groups was surprisingly well organized (Finland, secondary, female).

Using the software and exchanging products and ideas with distant pupils, my pupils were conscious of the other pupils' presence. My pupils realized that distant pupils were like them ... that they would conclude their own tales ... my students were carried away by this innovation (Italy, primary, female). 
These glimpses of a qualitatively new classroom were occasionally present in the teachers' comments, with the exception of the Greek teachers.

\subsection{Teacher comments related to 'Accountability'}

The teachers thought that CLEs have to be accountable along the lines that other learning environments have to. In addition to the emphasis on learning gains and skills, it also appeared an emphasis on the assessment of collaboration. Here, time and experience were also mentioned as important factors for the development of teacher mastery. CLEs were also seen as related to the development of ICT skills, although more general skills were mentioned as well.

Short assignments following the process of inquiry were maybe not cognitively deep, but principles of this type of work were surely introduced and in the second time these students can look better at the process and can set up better research problems (Finland, secondary, male).

This was of great importance, both for students and for teachers. Students came to realize themselves how they think about numbers - in some cases they just found out that they have been making wrong use of such terms as 'rational numbers'. But, what was really interesting is when some of them actually realized that they had deeper misconceptions (Greece, secondary, female).

The Italian teachers were the ones who mainly referred to new student proficiencies and potential skills to be assessed (collaboration skills, organizational and communicational skills), together with computer science and information organization skills. However, they did not seem so eager for quantifiable assessment. The Greek teachers were interested in a more personalized assessment, and were concerned about (traditional) learning gains.

You can detect an improvement in the skill of orienting within the paper material or even within the technological environments, to grasp information, to select, order it and classify (Italy, secondary, female).

The Dutch teachers were especially concerned with the issue of assessment. They preferred quantifiable assessment and more personalized types of assessment. They also cared for end products, assessment of process and future student benefits.

We want to do a traditional test, like the ones we used to do. To check what they have learned (The Netherlands, primary, male).

\subsection{Teacher comments related to "Software"}

The nature of the software was a prominent element in the teachers' conception of CLEs. Evaluations of aesthetics, usability, speed of execution, unexpected drawbacks, referred to the software, were further projected in the CLEs.

The login-method is very inefficient. It takes two e-mails to get them into your project. And when something goes wrong, they end up in the public part of Synergeia, thinking that they 
have arrived at the correct place. Leaving that aside, it is easy to learn how to use it. If you have no fear for buttons, you'll find your way... (The Netherlands, secondary, male).

CLEs were also seen as places of design freedom with respect to software, and the teachers felt free to ask for lots of changes. This idea is in accordance with a more general feeling that ICT is connected with freedom of action. The nature of the ITCOLE project, as a development project in which the teachers were asked at various phases to give feedback and suggestions for technical developers, may have also strengthened this feature in the teachers' responses.

There were no examples of deeper thinking about the interaction between software characteristics and learning mechanisms. The teachers spoke about the software tool that was used in the CLE in very concrete terms. The functionalities are useful for specific actions.

\subsection{Teacher comments related to 'Community'}

(a) Community: vertical

In putting CLEs within the broader institutional setting, issues of school organization and national organization appeared.

A negative feature was the organizational issues that had to be faced before the computer classroom could be used by students from different classes (Greece, secondary, male).

It should be, even from our side (teachers), more co-ordination and homogeneity in planning the activity (Italy, secondary, female).

Can this software be used really broadly in the Greek educational system? The time it needs to be realized seems extreme for the Greek educational system. It is also difficult to find a balance between talking face-to-face in the classroom and working in Synergeia (Greece, secondary, female).

The implementation of the CLEs introduced strains that made salient the shortcomings of school organization and of the national curriculum.

(b) Community: horizontal

By participating in the CLEs, many teachers in all four countries felt that their trust on students' ability to direct their own learning increased, and their relationships with students improved.

From my experience in the classroom I thought that students were not so interested about what other students where thinking. However when working with the project I saw a different picture. Students were really interested on what other students were thinking (Greece, secondary, male).

For me, as a teacher that was very instructive. I learned that students are able to learn a lot from each other (The Netherlands, primary, male).

Synergeia allowed the kids to see us as persons able to give them the opportunity to make more friends, to improve the way they used computers, which they really love to do, and first 
of all to create, through this software, contacts with people they don't know and that most likely think differently from them, therefore this has been very positive for them (Italy, primary, female).

\subsection{Teacher comments related to 'Norms'}

In the case of the Finish and Italian teachers, the few comments made about norms indicate that classroom norms combined well with the functioning of the CLE environment. The Greek and Dutch teachers' comments referred, occasionally, to a tension between current norms and the pedagogical principles that accompanied the CLEs.

However in the groups some students were able to dominate the discussion. I feel that I did not manage to deal effectively with this issue (Greece, primary, female).

Students are used to talk to each other in groups. They prefer to do this, instead of giving comments in Synergeia (The Netherlands, primary, male).

\section{Discussion and conclusions}

Putting together the results of our study we end up with both expected and unexpected outcomes. As expected, the teachers conceived CLEs as learning environments that are strongly student-centred, and give affordances to the students to take more learning responsibilities. Moreover, CLEs were seen as challenging for the teacher due to the transfer of responsibility and, perhaps more surprisingly, due to a sense of danger that teachers may get stuck in the role of just giving technical advice. CLEs were thought of as highly motivating for the students, appropriate for addressing students that are usually shy, without being boring for those who are achieving well in the more traditional school learning environments.

CLEs were conceived as environments that demand careful planning at several levels. Perhaps surprisingly, out of the teachers' comments from all countries came a message that participating in CLEs facilitates the development of professional expertise. However, specific strategies for student guidance in the classroom were not well articulated in the teachers' CLEs conceptions.

It was also expected that the software was a prominent element in the teachers' conception of CLEs. Within this dimension, the teachers mentioned issues related to aesthetics, usability, speed of execution, sensitivity of the whole CLE on drawbacks experienced in the software. Moreover, it emerged a sense of freedom to experiment with the varieties of software design. However, precise thoughts about the interplay between software design and student cognitive strategies were lacking among the teachers' comments.

As far as accountability is concerned, the teachers argued that CLEs should be assessed along similar lines with other learning environments. The Dutch teachers were particularly persistent in this respect. In addition to the emphasis on learning products, the teachers emphasized also the acquisition of certain skills (particularly ICT skills) and an effective collaboration. There were rare demands for quantifiable assessment of new competencies. 
In three of the four countries, with the exception of Greece, we got glimpses of a qualitatively advanced classroom where a CLE has been integrated. In such a classroom, ongoing evaluation is well-knit with student performance and at times cases of "flow of classroom work" were described.

Finally, for the teachers of all countries, participation in the CLEs influenced their relations with the student community, and increased their trust on students' competences. Moreover, the CLEs were experienced as "factors causing crisis" to the educational system and to the school organization. It seems that all the teachers realized that combining integration of CLEs in the classrooms and taking account of the national curricula is a demanding task.

Next to these common features, the teachers of the participating countries presented also a variety of profiles that differentiated them.

The Finnish teachers described CLEs in a positive light and found them fitting to the norms of their classrooms. They conceived them as environments that put special demands on students, and they reported many instances where they saw in CLEs the glimpses of a qualitatively new classroom. They were also the most articulate with respect to the guidance provided to the students.

The Italian teachers thought that CLEs resonate naturally with a collaborative and constructive pedagogy that they already espoused and practiced. In addition, they reported glimpses of a new classroom in CLEs, and they were the ones who felt most at ease with sharing learning responsibilities with their students. The Italian teachers did not find that CLEs were too demanding for the students and felt at ease to propose many different variations for the software tools that supported the CLEs in the ITCOLE project, in order to make them more effective.

The Finnish and Italian teachers were the ones who felt most comfortable with the pedagogy supporting CLEs. The two countries, however, differed strongly in the availability of PCs in order to implement the CLEs. As a result, advantages or disadvantages of the software had greater consequences for the Italian teachers - with fewer computers available.

The Dutch teachers were the ones who mostly stressed that CLEs have to be assessed according to similar principles as other learning environments. It is possible that their strong concern about accountability is related to the many innovations introduced in the Dutch education, and to their own effort to have a control on the influx of innovation based on clear assessment. However, this concern is tempered by references on new practices in the classrooms and the teachers' interest about the possibility of changing the distribution of learning responsibilities between teachers and students in the CLEs. Although, the Dutch teachers found CLEs motivating to the students, they were concerned about the duration of the enthusiasm.

The results of both quantitative and qualitative analyses indicate that the Greek teachers' attitudes to and beliefs about CLEs were still dominated by the teachers' central role and the actions that teachers do. The Greek teachers did not state that CLEs are demanding for the students, they did not report glimpses of a new classroom in the CLE environments, and their statements of accountability followed traditional lines. The Greek teachers' attitudes to and beliefs about CLEs were the ones that appear most distant from the features of a powerful learning environment. It could be claimed that they faced the biggest gap between the principles that guided the implementation of the CLEs and the hierarchical and authoritative national school culture. However, even 
in this case, CLEs were appreciated; the Greek teachers were concerned with the division of labour between teachers and students, as can be concluded from both the qualitative and the quantitative analysis of the data, and the category "Development of Professional Expertise" was strongly represented in the teachers' comments.

On the whole, the tension that the change in the division of labour between teachers and students creates is well represented in the teachers' attitudes to and beliefs about CLEs. The teachers realized the need for stronger student centeredness, and they tried to accommodate for it. It is interesting that the teachers paid attention to the signs of a new classroom culture, and that even in the cases of the teachers who did not mention that (i.e., the Greek teachers), there was positive acceptance of CLEs and a responsible attitude towards better planning. Moreover, participation in the CLEs made salient the issues of professional development for the teachers in all the participating countries, and issues of the current handicaps of school organization and national curriculum. All these factors resonate with the "reflection upon experience, classes taken, and the context or culture of the school" mentioned by Dexter et al. (1999), making CLEs particularly promising candidates for an introduction of ICT in the schools in order to catalyze pedagogical innovation.

In the side of concern, the teachers were not very reflective on the precise strategies by which they guided the students in the classrooms, and on the relation between specific features of the software used and student cognitive strategies. Moreover, although CLEs were found motivating even for students who are usually shy, some teachers were aware of the fragility of the students' interests. Hence, teachers will need more support in understanding the guidance of student learning and the social structure of the classroom when CLEs are implemented. This support could be embedded in the planning of CLEs' implementations since teachers are aware of the need for careful planning when implementing CLEs.

Finally, the teachers looked forward to clear assessments of the CLEs. Traditional measures like learning gains and skills were enlarged by the assessment of collaboration. However, contrary to our expectations, few teachers expressed demands for better assessment of the new competencies that may characterize student performance in the CLEs. Therefore, teachers need support in order to distinguish, in a precise way, the new qualitative characteristics of the CLE classrooms, before understanding the need for new assessment guidelines.

\section{Acknowledgements}

This research was conducted under the funding of the European Union for the Project ITCOLE in the Information Society Technologies (IST) framework; IST-00-III.2 'School of Tomorrow': http://www.euro-cscl.org.

We are grateful to all the teachers and students who participated in the ITCOLE-project, and to our colleagues that collaborated with us in this project: Philip Dean, Teemu Leinonen, Giedre Kligyte, Kai Hakkarainen, Minna Lakkala, Marjaana Veermans-Rahikainen, Jiri Lallimo, Essi Ryymin-Haatainen, Kati Korhonen, Wilfred Rubens, Bruno Emans, Henk Sligte, Beatrice Ligorio, Donatella Cesareni, Alessandra Talamo, Ilaria Mancini, Rudolf Ruland, Wolfgang Appelt, Antonio Gomez Skarmeta, Toni Martinez Carreras, José Antonio Pérez Sánchez, Pedro Garcia Lopez, and Gerry Stahl. 


\section{Appendix A}

Definitions of the categories of teachers' comments

\begin{tabular}{ll}
\hline Category & Definition \\
\hline $\begin{array}{l}\text { Student } \\
\text { Division of Labour: student role }\end{array}$ & $\begin{array}{l}\text { Refers to the responsibilities that students take } \\
\text { for their learning }\end{array}$ \\
Motivating the student & $\begin{array}{l}\text { Refers to the enthusiasm or the motivation of } \\
\text { students in the learning environment }\end{array}$
\end{tabular}

\section{Teacher}

Division of Labour: teacher role technical

Refers to the teacher as a provider of technical support

Division of Labour: teacher role planning

Refers to the teacher as planner of the activities that will take place in the classroom

Division of Labour: teacher role performance

Refers to the teachers performance in the classroom as she monitors and guides students

Long term pedagogical concerns

Refers to the interplay between the current events in the CLE and the expression of longer term pedagogical concerns on the side of the teacher

Development of professional expertise

Refers to teachers' reflection on the significance of participating in the CLE in the development of their pedagogical expertise

New classroom

Accountability: integrated

Refers to remarks of the teachers that show an integrated view for students' performances of understanding and assessment

Activity system

Refers to remarks that show that the teacher is perceiving the CLE as a working whole having a life of its own

\section{Accountability}

Accountability: learning gains

Refers to learning gains of a declarative kind from participating in the CLE

Accountability: collaboration

Refers to the assessment of the quality of collaboration 
Appendix A (continued)

\begin{tabular}{ll}
\hline Category & Definition \\
\hline Accountability: skills & Refers to skills that teachers find that get pro- \\
& moted through students participation in the \\
CLE
\end{tabular}

Software

Software

Community

Community: vertical

Community: horizontal
Refers to comments about the software that was used

Refers to CLEs' interaction with the demands of the broader community

Refers to comments that express changing in the relations between teachers and students due to the participation in the CLEs. It includes mainly references on increased trust

Norms

Norms

Refers to comments about new norms in the classroom or influence of older norms

\section{References}

Bransford, T. D., Brown, A. L., \& Cocking, R. R. (1999). How people learn: Brain, mind, experience and school. Washington: National Academy Press.

Dexter, S. L., Anderson, R. E., \& Becker, H. J. (1999). Teachers' views of computers as catalysts for changes in their teaching practice. Journal of Research on Computing in Education, 31(3), 221-239.

Dimitrakopoulou A. \& Petrou, A. (in press). Advanced collaborative distance learning systems for young students: design issues and current trends on new cognitive and metacognitive tools. Themes in Education.

Engeström, Y. (1987). Learning by expanding: An activity-theoretical approach to developmental research. Helsinki: Orienta-Konsultit.

Engeström, Y., Engeström, R., \& Suntio, A. (2002). Can a school community learn to master its own future? An activitytheoretical study of expansive learning among middle school teachers. In G. Wells \& G. Claxton (Eds.), Learning for life in the 21st century. Oxford: Blackwell Publishers.

Hakkarainen, K. (2003). Emergence of progressive inquiry culture in computer-supported collaborative learning. Learning Environments Research, 6(2), 199-220.

Hakkarainen, K., Rahikainen, M., Lakkala, M., \& Lipponen, L. (2002). Implementation of progressive inquiry in Finnish CSCL-settings, In M. Lakkala, M. Rahikainen, \& K. Hakkarainen (Eds.), Perspectives of CSCL in Europe: a review. A report for the European Commission, ITCOLE Project, IST-2000-26249. Available from http://www.eurocscl.org/site/itcole/D2_1_review_of_cscl.pdf.

Kollias, V. P., Mamalougos, N. G., Vamvakoussi, X., \& Vosniadou, S. (2003). Challenges of implementing CSCL designs in the Greek classrooms, in the symposium: implementing a pedagogically meaningful electronic learning environment in four different European School contexts. In 10th European biennial conference EARLI 2003, August 26-30, Padua, Italy. 
Kollias, V. \& Vosniadou, S. (2002). The status of CSCL research and practices in Greece. In M. Lakkala, M. Rahikainen, \& K. Hakkarainen (Eds.), Perspectives of CSCL in Europe: a review. A report for the European Commission, ITCOLE Project, IST-2000-26249. Available from http://www.euro-cscl.org/site/itcole/D2_1_review_of_cscl.pdf.

Koschmann, T. (1996). Paradigm shifts and instructional technology. In T. Koschmann (Ed.), CSCL: theory and practice of an emerging paradigm. Mahwah: Lawrence Erlbaum Associates.

Kozma, R. B. (2003). Technology and classroom practices: an international study. Journal of Research on Technology in Education, 36(1), 1-14.

Ligorio, B. \& Veermans, M. (this issue). Perspectives and patterns in developing and implementing web-based technology. Computers \& Education, doi: 10.1016/j.compedu.2005.04.008.

Ligorio, B., Cesareni, D., Mancini, I., \& Talamo, A. (2002). Collaboration, constructivism, community: the three "C" for the CSCL in Italy. In M. Lakkala, M. Rahikainen, \& K. Hakkarainen (Eds.), Perspectives of CSCL in Europe: a review. A report for the European Commission, ITCOLE Project, IST-2000-26249. Available from http://www.eurocscl.org/site/itcole/D2.

Molenaar, I., Scheltinga, H., Simons, R. J., \& Sligte, H. (2002). CSCL in the Netherlands. In M. Lakkala, M. Rahikainen, \& K. Hakkarainen (Eds.), Perspectives of CSCL in Europe: a review. A report for the European Commission, ITCOLE Project (IST-2000-26249). Available from http://www.euro-cscl.org/site/itcole/D2.

Perkins, D. (1995). Smart schools. New York: The Free Press.

Rubens, W., Emans, B., Leinonen, T., Skarmeta, A. G., \& Simons, R. J. (this issue). Design of web-based collaborative learning environments. Translating the pedagogical learning principles to human computer interface. Computers \& Education, doi: 10.1016/j.compedu.2005.04.007.

Schulman, L. S. (1986). Paradigms and research programs in the study of teaching: A contemporary perspective. In M. C. Wittrock (Ed.), Handbook of research on teaching. New York: Macmillan.

Vosniadou, S., \& Kollias, V. (2001). Information and communication technology and the problem of teacher training: myths, dreams and harsh reality. Themes in Education, 2(4), 341-365.

Vosniadou, S. (2001). How children learn, The International Bureau of Education. Available from http://www.ibe.unesco.org/International/Publications/EducationalPractices/EducationalPracticesSeriesPdf/prac07e.pdf.

Vosniadou, S., \& Kollias, V. (2003). Using collaborative, computer-supported, model building to promote conceptual change in science. In E. De Corte, L. Verschaffel, N. Entwistle, \& J. Van Merrienboer (Eds.), Powerful learning environments: Unravelling basic components and dimensions, advances in learning and instruction. New York: Pergamon. 